\title{
Brain Mechanisms of Propofol-Induced Loss of Consciousness in Humans: a Positron Emission Tomographic Study
}

\author{
Pierre Fiset, ${ }^{1,3}$ Tomás Paus, ${ }^{2}$ Thierry Daloze, ${ }^{1}$ Gilles Plourde, ${ }^{1}$ Pascal Meuret, ${ }^{1}$ Vincent Bonhomme, ${ }^{1}$ \\ Nadine Hajj-Ali, ${ }^{4}$ Steven B. Backman, ${ }^{1,3}$ and Alan C. Evans ${ }^{2}$ \\ Departments of ${ }^{1}$ Anesthesiology and ${ }^{2}$ Neurology and Neurosurgery and ${ }^{3}$ McGill University Health Center, McGill

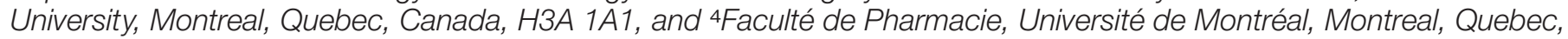 \\ Canada H3C 3J7
}

\begin{abstract}
In the present study, we used positron emission tomography to investigate changes in regional cerebral blood flow (rCBF) during a general anesthetic infusion set to produce a gradual transition from the awake state to unconsciousness. Five righthanded human volunteers participated in the study. They were given propofol with a computer-controlled infusion pump to achieve three stable levels of plasma concentrations corresponding to mild sedation, deep sedation, and unconsciousness, the latter defined as unresponsiveness to verbal commands. During awake baseline and each of the three levels of sedation, two scans were acquired after injection of an $\mathrm{H}_{2}{ }^{15} \mathrm{O}$ bolus. Global as well as regional CBF were determined and correlated with propofol concentrations. In addition, blood flow changes in the thalamus were correlated with those of the entire scanned volume to determine areas of coordinated changes.

In addition to a generalized decrease in global CBF, large regional decreases in CBF occurred bilaterally in the medial
\end{abstract}

thalamus, the cuneus and precuneus, and the posterior cingulate, orbitofrontal, and right angular gyri. Furthermore, a significant covariation between the thalamic and midbrain blood flow changes was observed, suggesting a close functional relationship between the two structures.

We suggest that, at the concentrations attained, propofol preferentially decreases $\mathrm{rCBF}$ in brain regions previously implicated in the regulation of arousal, performance of associative functions, and autonomic control. Our data support the hypothesis that anesthetics induce behavioral changes via a preferential, concentration-dependent effect on specific neuronal networks rather than through a nonspecific, generalized effect on the brain.

Key words: anesthesia; PET; arousal; consciousness; thalamus; reticular formation; cerebral blood flow; propofol
The search for a neural substrate of consciousness has been the subject of increased scientific effort in recent years. Although it is difficult to provide an all-encompassing definition of the term "consciousness," it is useful to make a distinction between the level and content of consciousness: the former is generally associated with arousal, whereas the latter concerns the content of subjective experience (Frith et al., 1999). In the present paper, the term consciousness is used in reference to the level of arousal.

Since the pioneering work of Jasper (1949) and Moruzzi and Magoun (1949), the thalamus and the brainstem reticular formation have been known to play a critical role in the regulation of levels of consciousness. More recent work in nonhuman species provided evidence that neuronal oscillations in the reticular thalamic nucleus are intimately linked to the variations in sleepwaking cycle (Steriade and Deschenes, 1984; Steriade and Llinas, 1988; Steriade et al., 1993). In particular, GABAergic cells of the reticular thalamic nucleus seem to control bursting activity of the thalamocortical neurons and, in turn, modulate cortical activity

\footnotetext{
Received Feb. 2, 1999; revised April 16, 1999; accepted April 19, 1999.

This study was supported by the Canadian Medical Research Council, le Fonds de la Recherche en Santé du Québec (G.P.), le Centre Hospitalier Universitaire de Liège, Belgium (V.B.) and the Associated Anesthetists of the Royal Victoria Hospital. We thank Drs. Barbara E. Jones and M. Catherine Bushnell for their input in this manuscript.

Correspondence should be addressed to Dr. Pierre Fiset, Department of Anesthesiology, Royal Victoria Hospital, 687 Pine Avenue West, Room S5.05, Montreal, Quebec, Canada H3A 1A1.

Copyright (C) 1999 Society for Neuroscience $\quad 0270-6474 / 99 / 195506-08 \$ 05.00 / 0$
}

(Steriade et al., 1993; Destexhe et al., 1994). In humans, much less is known about the relationship between the intrathalamic nuclei activity and consciousness. Reports on the recording of unit activity in the human thalamus are sparse, and lesion studies (Lugaresi et al., 1986; Kinney et al., 1994) provide only a limited static picture of the system. On the other hand, several brain imaging studies have shown regional cerebral blood flow (rCBF) variations in the human thalamus in relation to various states of consciousness, including sleep (Maquet et al., 1996, 1997; Hofle et al., 1997) vigilance (Paus et al., 1997), and attention (Kinomura et al., 1996).

Pharmacological studies on anesthetic effects suggest that a variety of neurochemical routes lead to the same end point, namely the change of the level of consciousness. Thus, the currently used general anesthetics may act through ligand-gated ion channels of the GABA (Hales and Lambert, 1991; Yeh et al., 1991; Orser et al., 1994), NMDA (Lodge et al., 1982) (Anis et al., 1983), and muscarinic (Lydic et al., 1993; Keifer et al., 1994) receptors. It is not known, however, whether these cellular events exert their action by affecting specific structures of the brain.

In the present study, we manipulated the level of consciousness using propofol, an anesthetic drug widely used in clinical practice to induce and maintain general anesthesia. Propofol was chosen because its concentration-effect relationships are well established and predictable (Dunnet et al., 1994; Forrest et al., 1994; Casati et al., 1999). We infused propofol with a computer-controlled infusion pump (CCIP) to maintain steady-state plasma concen- 
trations and, in turn, a stable effect corresponding successively to light sedation, deep sedation, and unconsciousness. At the same time, we used positron emission tomography (PET) to measure absolute and relative values of rCBF and electroencephalography (EEG) to assess concurrent changes in the electrocortical arousal. We found that the thalamic blood flow decreased as a function of the propofol level above and beyond a decrease in global CBF.

\section{MATERIALS AND METHODS}

Subjects. The study was approved by the Research and Ethics Committee of the Montreal Neurological Institute and Hospital. Five healthy righthanded subjects (two females) participated in the study after giving written informed consent (age, $25.4 \pm 3.36$ years). All underwent a comprehensive medical evaluation and had no history of neurological disorders or intolerance to anesthesia.

Experimental design. We did not objectively assess the component of consciousness related to the appreciation or awareness of afferent inputs. Our definition of consciousness, i.e., response to verbal commands, is simple yet operationally useful in the sense that it globally evaluates all the aspects of the conscious response to a standard stimulus.

Three different levels of sedation (mild sedation, deep sedation, and unconsciousness) were induced and maintained with propofol administered using a computer-controlled infusion pump (CCIP). Volunteers were also studied during an awake baseline state. The following order of conditions was used: awake baseline (baseline), mild sedation (level 1), deep sedation (level 2), and unconsciousness defined as an absence of response to verbal commands (level 3 ). Thus, the subjects always received an increasing concentration of propofol to avoid delays encountered by the elimination of the drug from the brain if a decreasing concentration order had been used.

At each condition, two 3 min PET scans were acquired with a Scanditronix (Uppsala, Sweden) PC-2048B tomograph, and arterial blood samples were drawn to calculate the absolute values of rCBF. Blood was also drawn for determination of arterial blood gases and propofol plasma concentrations. During the scans, the subjects were blindfolded and EEG, electrocardiogram, systemic arterial blood pressure, and pulse oximetry were recorded. During all scans oxygen was provided through a loosely fitting face mask at a rate of $31 / \mathrm{min}$. Between each scan the state of consciousness was assessed by asking the volunteer to move his or her toes and squeeze the investigator's hand. Throughout the study, the subjects were closely monitored by an anesthesiologist (P.F., T.D., or G.P.). Resuscitation material was readily available in the scanner room.

To facilitate localization of the regional changes in CBF, we obtained high-resolution T1-weighted magnetic resonance images (MRIs; 160 contiguous sagittal slices, $1 \mathrm{~mm}$ thick) from a Philips (Besl, The Netherlands) Gyroscan ACS imager (1.5 T) for each subject.

Propofol Infusion. Propofol was infused with a CCIP; the infusion program STANPUMP (developed by Steven L. Shafer, Department of Anesthesiology, Stanford University, Stanford, CA) was used to control a Harvard Apparatus (Holliston, MA) 22 pump. A target concentration of propofol was rapidly reached by the administration of a bolus dose and was maintained by an infusion with an exponentially declining rate. The dosage and rate of propofol infusion were based on pharmacokinetic parameters obtained by Tackley et al. (1989) in a population with demographic characteristics similar to those of our volunteers.

In addition to the awake baseline condition (baseline, $0.0 \mu \mathrm{g} / \mathrm{ml}$ of propofol in plasma), the following three levels of propofol were targeted: level $1,0.5 \mu \mathrm{g} / \mathrm{ml}$ plasma when the volunteer is awake and mildly sedated and readily follows commands; level $2,1.5 \mu \mathrm{g} / \mathrm{ml}$ plasma when the volunteer is deeply sedated, his or her speech is sluggish, and reactions to verbal orders are slow; and level $3,2.5-3.0 \mu \mathrm{g} / \mathrm{ml}$ plasma when the volunteer is unconscious and does not respond to verbal orders but breathes spontaneously.

The plasma concentration of propofol was assessed with HPLC (Plummer, 1987) using arterial blood samples obtained at least 5 min after the target effect site concentration was reached and 4 min before the commencement of each scan.

$E E G$. Brain electrical activity was recorded using $\mathrm{Ag} / \mathrm{AgCl}$ electrodes placed over the left hemisphere $\left(\mathrm{F}_{4}, \mathrm{P}_{4}\right.$, and $\left.\mathrm{O}_{2}\right)$ and at the vertex $\left(\mathrm{C}_{\mathrm{z}}\right)$ and referenced to the right earlobe $\left(\mathrm{A}_{2}\right)$ (Electrode Nomenclature Committee, 1994). A horizontal electro-oculogram was obtained from two electrodes placed at the outer canthi of each eye, and an electromyogram (EMG) was recorded from an electrode placed on the chin. The elec- trodes were filled with conductive gel and glued to the scalp with collodion and a piece of gauze. The electrode impedance was considered acceptable if $<10 \mathrm{k} \Omega$.

Brain electrical activity was amplified (bandpass, 0.3-100 Hz) and sampled at $256 \mathrm{~Hz}$ with Monitor software (Stellate Systems, Montreal, Quebec, Canada) and stored on disk for subsequent analysis. For each 3 min epoch corresponding to a CBF scan, the EEG activity present at various frequency bands was determined using fast Fourier transform (Rhythm software, Stellate Systems). The following frequency bands were used: $\delta, 1.5-4.0 \mathrm{~Hz} ; \theta, 4.5-8.0 \mathrm{~Hz} ; \alpha, 8.5-11.5 \mathrm{~Hz} ; \sigma, 12.0-15.0 \mathrm{~Hz}$; $\beta, 18.0-30.0 \mathrm{~Hz}$; and $\gamma, 30.5-57.0 \mathrm{~Hz}$. For the present analysis, only data from $\mathrm{F}_{4}-\mathrm{A}_{2}$ were used.

EEG epochs containing obvious muscle activity or eye blinks were rejected. Data from $\mathrm{F}_{4}-\mathrm{A}_{2}$ were subjected to an ANOVA for repeated measures to evaluate the effect of propofol level (baseline and levels 1-3) on the total and relative power at each frequency level $(\alpha, \delta, \theta, \sigma, \beta$, and $\gamma$ ). The Greenhouse-Geisser procedure was used to adjust the degrees of freedom. Tukey's honestly significant difference test was used for post hoc tests (Kirk, 1982).

Measurement and analysis of $r C B F$. Values of $\mathrm{rCBF}$ were measured with a Scanditronix PC-2048B eight-ring 15-slice tomograph. The axial view of this scanner is $9 \mathrm{~cm}$, and in this study, the subjects were placed in the scanner so that the brain was scanned from approximately $z=48$ to $z=-44 \mathrm{~mm}$. The distribution of $\mathrm{rCBF}$ was measured during each 3 min scan using the ${ }^{15} \mathrm{O}$-labeled $\mathrm{H}_{2} \mathrm{O}$ bolus method (Raichle et al., 1983). For each scan, $30 \mathrm{mCi}$ of ${ }^{15} \mathrm{O}$-labeled $\mathrm{H}_{2} \mathrm{O}$ was injected into the left antecubital vein. Arterial blood samples were taken from a catheter placed in the right radial artery. The sinograms were reconstructed using an $18 \mathrm{~mm}$ Hanning filter.

Absolute $r C B F$. Arterial blood samples were collected manually at $5 \mathrm{sec}$ intervals and assayed in a well counter calibrated with respect to the tomograph. CBF was calculated using the two-compartment, weighted integration method of Ohta et al. (1996). Cerebral perfusion maps (K1 maps) were generated for each scan using the sum of the native PET image across all frames. Mean whole-brain CBF values were then obtained by averaging the $\mathrm{K} 1 \mathrm{map}$.

The averaging of masked $\mathrm{K} 1$ maps allowed calculation of mean $\mathrm{CBF}$ values in the gray and white matter. The masks were standard probabilistic maps of gray or white matter co-registered with each K1 map by means of an automatic registration program (Woods et al., 1993). A probability of 0.6 was chosen as the cutoff point for a voxel to be of gray or of white matter, respectively.

The mean CBF of the regions of interest was calculated. The coordinates of significant peaks observed after statistical analysis of the relative $\mathrm{CBF}$ images were back-transformed into the coordinates of each individual $\mathrm{K} 1 \mathrm{map}$ and served as the center of a $7 \mathrm{~mm}$ radius volume of interest. The average $\mathrm{CBF}$ value in that region was then extracted.

Normalized $r C B F$. To identify the brain regions where propofol induced changes in blood flow beyond those observed globally, we analyzed the effects of propofol on normalized rCBF. This analysis was limited to the initial $60 \mathrm{sec}$ period of the $3 \mathrm{~min}$ scan. First, between-scan and between-subject differences in global CBF were removed by proportional normalization: in each scan, count values in all voxels were multiplied by a constant, based on the mean count value of all gray matter voxels for the given scan, so that the resulting global mean had a value of 50 in all scans and subjects. The gray matter voxels were defined by a probabilistic gray matter mask (gray matter $p>0.5$ ). The use of the gray matter mask ensures that the global changes in CBF in the area of greatest neuronal activity are removed. Second, PET images were coregistered with the individual MRIs (Woods et al., 1993) and transformed into stereotaxic space (Talairach and Tournoux, 1988) by means of an automated feature-matching algorithm (Collins et al., 1994).

To assess the significance of the linear relationship between the plasma level of propofol and normalized $\mathrm{rCBF}$, a propofol regression map was calculated. The following calculations were performed for each of the three-dimensional volume elements (voxels) constituting a volume. The data set consisted of normalized rCBF obtained in five subjects, each scanned twice during each of the three propofol conditions, yielding a total of $30 \mathrm{CBF}$ volumes. Because of excessive movements during scanning, however, four scans obtained at levels 2 and 3 in one of the subjects had to be excluded, leaving us with a total of 26 volumes. The effect of propofol on $\mathrm{CBF}$ was assessed by means of an analysis of covariance (ANCOVA) (Sokal and Rohlf, 1981), with subjects as a main effect and the plasma level of propofol as a co-variate. The subject effect was removed, and the parameter of interest was the slope of the propofol 
Table 1. Vital signs: mean \pm SD for all subjects during baseline and levels of sedation

\begin{tabular}{|c|c|c|c|c|}
\hline Sign & Baseline & Level 1 & Level 2 & Level 3 \\
\hline $\mathrm{P}_{\mathrm{CO}_{2}}$ & $40 \pm 4.2$ & $40 \pm 3.5$ & $46 \pm 5.9$ & $44 \pm 5.0$ \\
\hline Heart rate $(\mathrm{bpm})$ & $63 \pm 9.8$ & $57 \pm 6.6$ & $57 \pm 5.9$ & $63 \pm 7.1$ \\
\hline Sys BP (mmHg) & $123 \pm 8.2$ & $115 \pm 7.5$ & $107 \pm 7.2$ & $95 \pm 10.6^{*, * * *}$ \\
\hline Diast BP (mmHg) & $66 \pm 6.0$ & $64 \pm 5.7$ & $60 \pm 4.7$ & $56 \pm 6.3$ \\
\hline Mean BP (mmHg) & $85 \pm 6.8$ & $81 \pm 6.2$ & $75 \pm 3.8$ & $69 \pm 8^{*, * * *}$ \\
\hline
\end{tabular}

Sys BP, Systolic blood pressure; Diast BP, diastolic blood pressure.

*Different from baseline $(p<0.01)$.

$* *$ Different from level $1(p<0.05)$.

Table 2. EEG values $\left(\mu \mathrm{v}^{2} / \mathrm{sec}\right)$ for total power and percent of total (relative) power for frequency bands

\begin{tabular}{lclllll} 
& Total power & $\delta(\%)$ & $\theta(\%)$ & $\alpha(\%)$ & $\sigma(\%)$ & $\beta(\%)$ \\
\hline Baseline & 259 & 20.7 & 16.4 & 14.65 & 7.69 & 16.6 \\
Level 1 & 282 & 19.8 & 13.7 & 11.8 & 11.44 & 18.6 \\
Level 2 & 519 & 19.5 & 11.6 & 13.5 & $14.24^{*}$ & 19.3 \\
Level 3 & $730^{* *, \dagger}$ & 26.7 & 13.1 & 16.6 & $14.61^{\ddagger}$ & 12.5 \\
\hline
\end{tabular}

${ }^{*}$ Level $2>$ Baseline $(p<0.021)$.

$* *$ Level $3>$ Baseline $(p<0.004)$.

${ }^{\dagger}$ Level $3>$ Level $1(p<0.005)$.

${ }^{\ddagger}$ Level $3>$ Baseline $(p<0.015)$.

Level $3<$ Baseline $(p<0.013)$.

effect on normalized rCBF. An estimate of the slope, $\beta_{\mathrm{PROP}}$, and its SD, $s$, were obtained by least-squares fitting of the model (ANCOVA) at each voxel. A total of 26 values of the co-variate were used, corresponding to the 26 volumes in the data set. The degrees of freedom (df) of the estimate of the SD $(s)$ were increased from $20(26-5-1)$ by pooling $\mathrm{s}$ across all voxels, and this replaced a voxel $\mathrm{s}$ in the denominator of the $t$ statistic, $t=\beta_{\mathrm{PROP}} /$ pooled $s$, so that its distribution was normal. The resulting $t$ statistic map tested whether, at a given voxel, the slope of the regression was significantly different from zero; the presence of a significant peak was tested by a method based on three-dimensional Gaussian random-field theory, which corrects for the multiple comparisons involved in searching across a volume (Worsley et al., 1992). Values equal to or exceeding a criterion of $t=3.5$ were considered significant $(p<$ 0.0004 , two-tailed, uncorrected), yielding a false-positive rate of 0.5 in 200 resolution elements (each of which has dimensions $7.7 \times 18 \times 18$ $\mathrm{mm}$ ), which is approximately the volume of brain gray matter.

In addition to the above propofol regression map, a regional regression map was generated to assess the significance of the relationship between $\mathrm{CBF}$ values in the thalamus and those obtained at each voxel of the entire scanned volume. This was done to reveal brain regions that showed a coordinated blood flow response in the thalamus and in other regions to the changing plasma levels of propofol. CBF values in the thalamus were first derived by positioning a spherical volume of interest (radius, $8 \mathrm{~mm}$ ) at the center of the peak defined by the propofol regression. Subsequently, the same statistical procedures were used when calculating the propofol regression map: subject effect was removed, and the parameter of interest was the slope $\beta_{\text {THAL }}$ of the effect of CBF in the thalamus on $\mathrm{CBF}$. Assessment of significance for this parameter (i.e., generation of a $t$ map) was performed in the same manner as for the propofol regression.

\section{RESULTS}

\section{Propofol concentration}

HPLC analysis of plasma demonstrated that the concentrations achieved were very similar to those targeted. The measured concentrations were as follows (mean $\pm \mathrm{SD}$ ): level 1, $0.445 \pm$ $0.070 \mu \mathrm{g} / \mathrm{ml}$ (target, $0.5 \mu \mathrm{g} / \mathrm{ml}$ ); level 2, $1.35 \pm 0.11 \mu \mathrm{g} / \mathrm{ml}$ (target, $1.5 \mu \mathrm{g} / \mathrm{ml}$ ); and level 3, $2.67 \pm 0.5 \mu \mathrm{g} / \mathrm{ml}$ (target, 2.5-3.0 $\mu \mathrm{g} / \mathrm{ml}$ ). The mean and median absolute errors of propofol plasma concentrations in all subjects were 12 and $8 \%$, respectively, of the values predicted by the CCIP.

\section{State of consciousness}

All volunteers were conscious but mildly sedated at level 1, such that they responded to verbal commands and reported being slightly drowsy. At level 2, four subjects were deeply sedated, as indicated by their slurred speech and slow responses to verbal commands, whereas one volunteer was unconscious. At level 3, all five volunteers were unconscious.

\section{Cardiovascular parameters}

Heart rate and $\mathrm{P}_{\mathrm{CO}_{2}}$ did not change at levels 1-3 compared with baseline. There was a significant drop in systolic and diastolic blood pressure at level 3 compared with the baseline and with level 1, as illustrated in Table 1. A small nonsignificant increase in $\mathrm{P}_{\mathrm{CO}_{2}}$ was observed at levels 2 and 3 compared with baseline.

\section{Electroencephalogram}

Table 2 shows the effect of propofol on EEG. There was a significant increase in total power during level 3 compared with baseline and level 1. There was a significant increase in $\sigma$ relative power during levels 2 and 3 compared with baseline. There was finally a significant decrease in $\gamma$ power during level 3 compared with baseline. This effect remained significant when the $\gamma$ relative power from the chin EMG was used as a time-varying covariate.

\section{Absolute CBF}

Figure 1 shows a $20.2 \%$ decrease in global CBF, from 40.1 to 32.1 $\mathrm{ml} \cdot 100 \mathrm{gm}^{-1} \cdot \mathrm{min}^{-1}$, between baseline and level 3 . The ANOVA showed a significant main effect of level $(F=4.63 ; p=$ 0.0226 ), and a post hoc paired $t$ test comparing each of the levels showed a statistically significant difference between baseline and level $3(p<0.05)$ and a borderline difference between levels 1 and 3 .

The white and gray matter compartments were defined with the aid of the respective probabilistic maps. The two-way repeated measures ANOVA revealed a significant main effect of tissue 


\section{Global Cerebral Blood Flow}

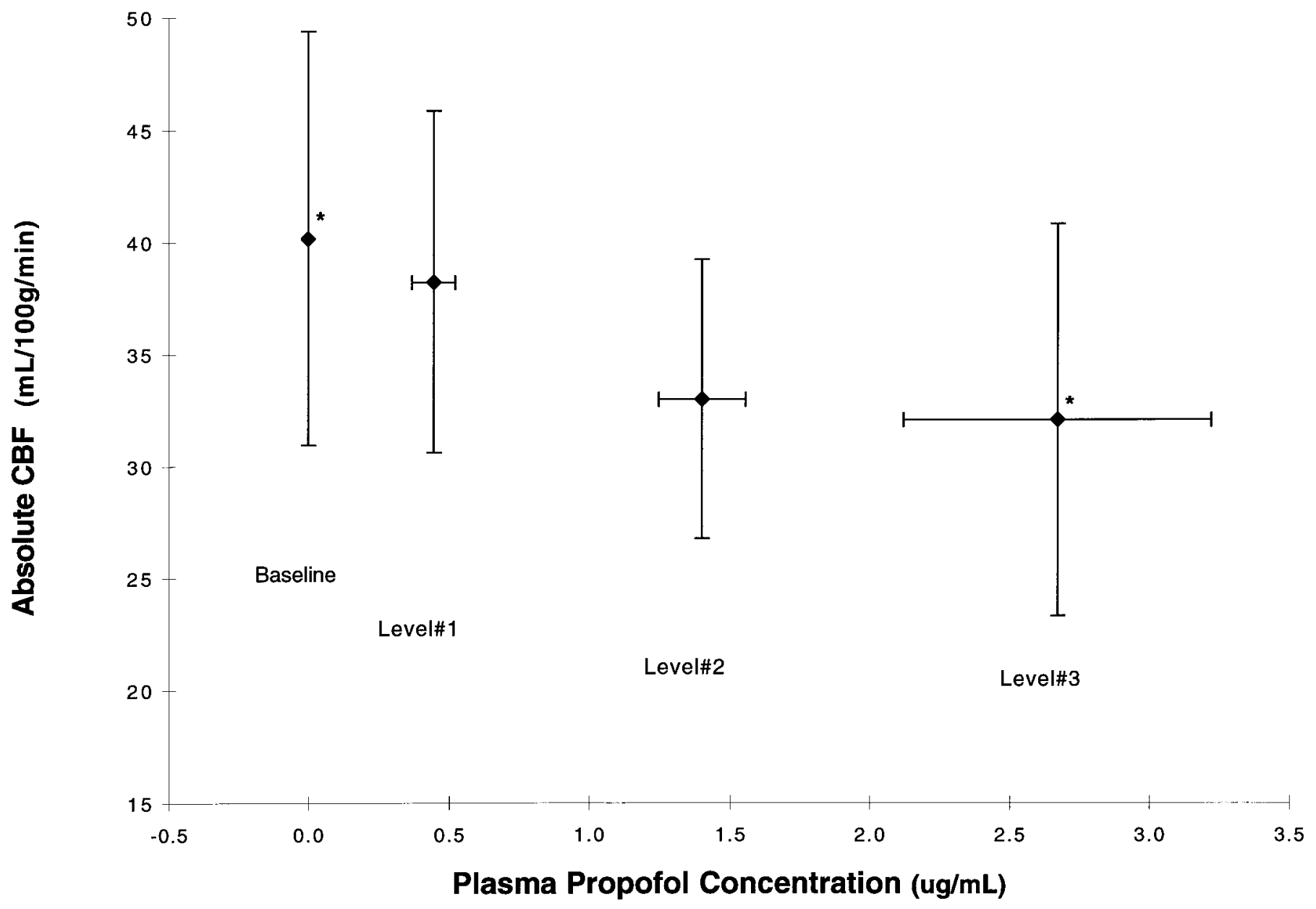

Figure 1. Absolute cerebral blood flow changes as a function of the baseline and the three levels of propofol expressed as the mean concentration of propofol \pm SD. ${ }^{*}$ Statistically significant difference $(p<0.05)$.

type $(F=4.52 ; p=0.0477)$ but no significant interaction between level and tissue type.

\section{Normalized rCBF}

The results of the regression of propofol levels versus rCBF are summarized in Table 3. As the plasma concentration of propofol increased, normalized rCBF decreased in the thalamus (Figs. 2, $3 A$ ) and in the parieto-occipital cortices, cuneus, precuneus, and posterior cingulate (Fig. $3 A$ ).

On the other hand, significant positive correlations between propofol and $\mathrm{rCBF}$ were observed in the cerebellum, the medial frontal cortex, and the left temporal pole.

The thalamus-based regional regression revealed a positive correlation between the thalamic CBF and the midbrain, upper midbrain, and left orbitofrontal cortex (Table 3, Fig. 3B).

\section{DISCUSSION}

Propofol induced a decrease in absolute CBF throughout the white and gray matter. Using the normalized $\mathrm{rCBF}$ data, we found that this effect is particularly pronounced in the medial thalamus, the cuneus and precuneus, the posterior cingulate and orbitofrontal gyri, and the right angular gyrus. The propofol- related variations in the thalamic blood flow were statistically linked with those in the midbrain reticular formation, thus suggesting a close functional relationship between the two brain structures.

\section{Propofol and global cerebral blood flow}

Our finding that propofol produces a decrease in the global CBF is consistent with the results of several animal studies that used a variety of techniques, including cerebral venous outflow measurement (Langerkranser et al., 1997), labeled tracer injection (Werner et al., 1993; Todd and Weeks, 1996), and ${ }^{133}$ Xe (Van Hemelrijck et al., 1990). A global decrease in CBF, measured by middle cerebral artery Doppler (Eng et al., 1992) and ${ }^{133} \mathrm{Xe}$ (Pinaud et al., 1990; Newman et al., 1995), has also been reported in human subjects.

In the present study, we report a decrease in the mean systemic arterial blood pressure with increasing concentrations of propofol. When autoregulation of the cerebral vasculature is intact, changes in systemic arterial blood pressure ranging between 50 and $150 \mathrm{mmHg}$ do not result in variations of CBF. It has been shown in animals (Van Hemelrijck et al., 1990; Werner et al., 1993; Langerkranser et al., 1997) and in humans (Salord et al., 


\begin{tabular}{|c|c|c|c|c|c|}
\hline Structure & Putative area of Brodman & $x$ & $y$ & $z$ & $t$ \\
\hline \multicolumn{6}{|l|}{$\begin{array}{l}\text { Regression of rCBF vs propofol } \\
\text { level }\end{array}$} \\
\hline \multicolumn{6}{|l|}{ Negative correlations } \\
\hline Right parietal & 39 & 42 & -57 & 48 & -6.8 \\
\hline Left parietal & 7 & -18 & -72 & 46 & -6.7 \\
\hline Left Parieto-occipital sulcus & 7 and 19 & -9 & -74 & 44 & -6.6 \\
\hline Right Parieto-occipital sulcus & 7 and 19 & 24 & -74 & 36 & -4.87 \\
\hline Right occipital subcortical & 40 & 40 & -64 & 39 & -6.25 \\
\hline Cuneus & 18 & 1 & -81 & 24 & -6.7 \\
\hline Precuneus & 7 & -2 & -74 & 39 & -6.7 \\
\hline Posterior cingulate & 30 & -1 & -62 & 16 & -5.76 \\
\hline Posterior cingulate & 31 & 4 & -61 & 30 & -5.27 \\
\hline Medial thalamus & & 3 & -18 & 5 & -5.62 \\
\hline Left prefrontal (subcortical) & 11 & -32 & 39 & -15 & -5.26 \\
\hline Right pre-frontal (subcortical) & 11 & 31 & 46 & -17 & -5.23 \\
\hline Prefrontal (midline) & 11 & 0 & 34 & -23 & -4.5 \\
\hline Frontal & 45 & 56 & 33 & 24 & -4.89 \\
\hline \multicolumn{6}{|l|}{ Positive correlations } \\
\hline Cerebellum & & 1 & -59 & -12 & 8.07 \\
\hline Medial frontal & 24 & -1 & 5 & 50 & 5.72 \\
\hline Left temporal pole & 20 & -43 & 3 & -27 & 5.06 \\
\hline \multicolumn{6}{|l|}{ Covariation with thalamus } \\
\hline Upper midbrain & & 0 & -19 & -8 & 4.92 \\
\hline Left orbitofrontal & & -31 & 48 & -14 & 4.56 \\
\hline Midbrain & & -7 & -28 & -27 & 4.26 \\
\hline
\end{tabular}

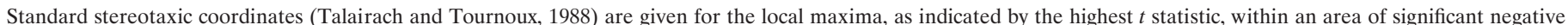

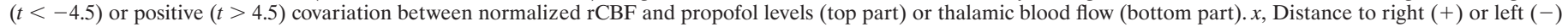
of the midsagittal line; $y$, distance anterior $(+)$ or posterior $(-)$ to the anterior commissure; $z$, distance above $(+)$ and below $(-)$ the intercommissural line.

1995) that autoregulation is preserved when propofol is administered in concentrations similar to those used in our study. Therefore, we suggest that the changes in CBF reported here do not result from the variation in blood pressure but instead are a reflection of the decreased cerebral metabolic requirements induced by anesthesia.

\section{Propofol effects on the reticulothalamic system}

The strong negative correlation between $\mathrm{rCBF}$ in the medial thalamus and propofol concentration suggests that propofol acts on the reticulothalamic system when loss of consciousness is induced. We have since replicated this finding in another group of subjects (Fiset et al., 1997). The observed covariation between the thalamic and midbrain blood flow is consistent with the role of the thalamus and the ascending reticular activating system (ARAS) in the regulation of wakefulness (Steriade et al., 1990; Paus et al., 1997). Electrophysiological studies in animals have shown that a progression from awake slow-wave sleep is associated with a decreased firing of neurons in the brainstem reticular activating system and a disfacilitation of thalamocortical relay neurons (Steriade et al., 1990; Jones, 1994). Furthermore, thalamocortical interactions expressed, for example, as $40 \mathrm{~Hz}$ oscillations are decreased in natural sleep (Llinás and Paré, 1991) and during general anesthesia (Plourde and Picton, 1990; Plourde and Boylan, 1991; Plourde et al., 1998). Our results suggest that the reticulothalamic system plays a central role in the modulation of consciousness by general anesthetics. It is important to note that similar variations in the thalamic CBF were also observed during natural transitions between waking and slow-wave sleep (Hofle et al., 1997; Maquet et al., 1997), between high and low vigilance levels (Paus et al., 1997), and between high and low alertness (Kinomura et al., 1996).

It is believed that neural effects of propofol are mediated at least in part by the activation of the $\mathrm{GABA}_{\mathrm{A}}$-ionophore receptor complex (Concas et al., 1991; Pedutto et al., 1991; Tanelian et al., 1993). The interaction between the GABAergic cells of the reticularis and the perigeniculate nuclei and the excitatory thalamocortical relay neurons is responsible for the generation of spindle wave activity recorded during slow-wave sleep (von Krosigk et al., 1993). This suggests that the thalamic deactivation we report in association with propofol-induced modulation of consciousness may result from a direct effect on the $\mathrm{GABA}_{\mathrm{A}}$ receptor complex of that circuit. This explanation is consistent with the decreases in $\mathrm{CBF}$ resulting from the pharmacological stimulation of $\mathrm{GABA}_{\mathrm{A}}$ receptors, suggesting that inhibitory postsynaptic neurotransmission may be associated with decreases in rCBF (Gjedde, 1997; Roland and Friberg, 1988).

\section{Propofol effects on cortical activity}

In the present study, we found an overall decrease of absolute $\mathrm{CBF}$ in the gray matter, which may reflect an overall decrease in cortical neuronal activity. Direct inhibitory effects of propofol on cortical layers II, IV, V, and VI have been reported (Angel, 1993) and could underlie the cortical deactivation. Alternatively, a decreased cortical activity may be secondary to decreased activity in the ARAS and thalamocortical systems.

In addition to the overall decrease in cortical CBF produced by propofol, we observed particularly pronounced effects in several cortical regions. The medial parieto-occipital cortex was one of 


\section{Relative CBF (Thalamus)}

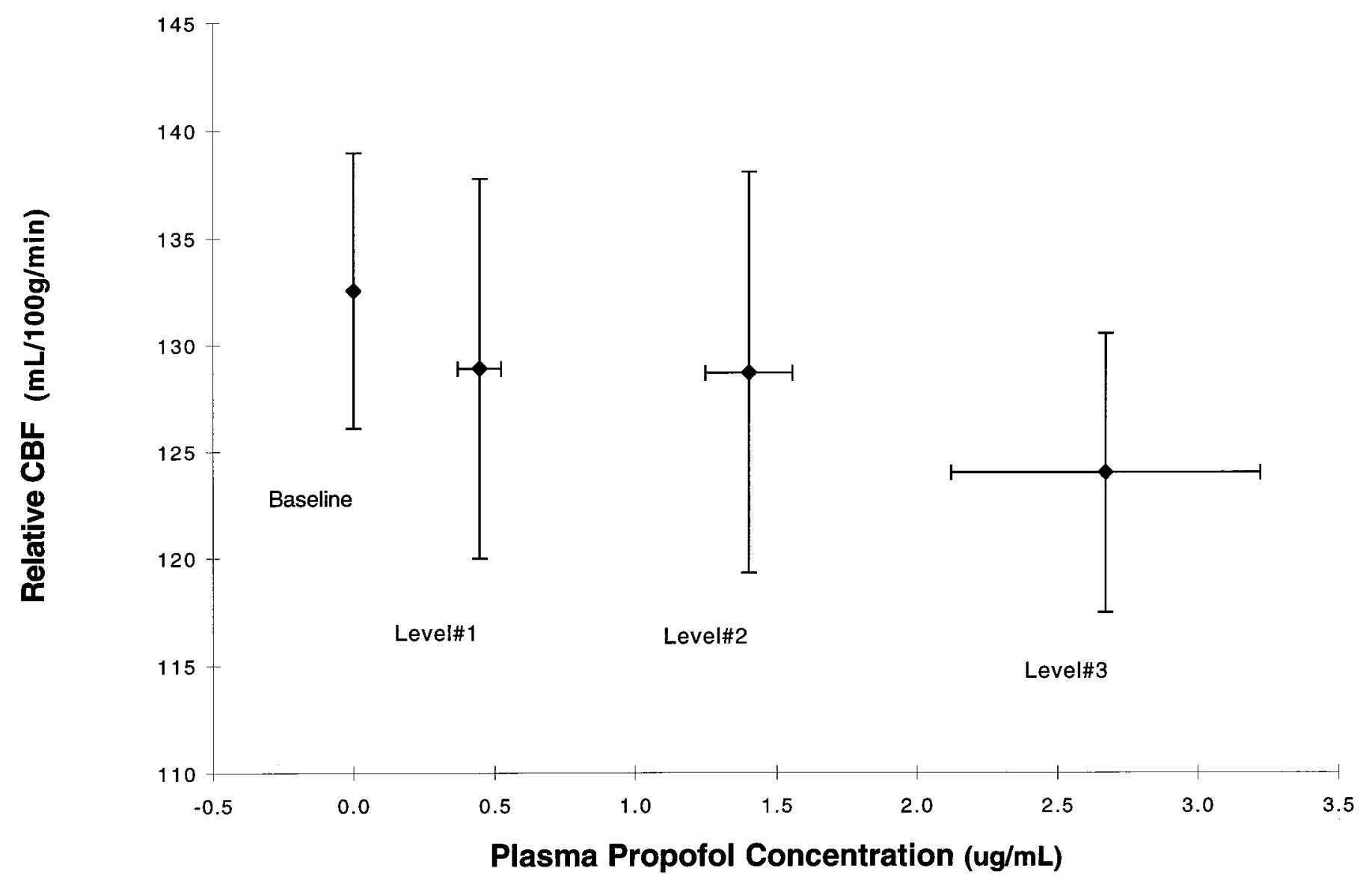

Figure 2. Normalized thalamic blood flow as a function of propofol levels. There is significant negative correlation with a peak in the medial thalamus $(t=5.62)$.

the regions particularly affected. It includes the cuneus, precuneus, posterior cingulate cortex, and right angular gyrus. These areas are implicated in visual associative activities, integration of sensory information, processing of spatial information, and evaluation sensory inputs in the service of spatial orientation and memory.

Changes in activation of the medial occipital area have been reported in other PET studies concerned with the mechanisms modulating the level of consciousness. Hofle et al. (1997) in a sleep study, Paus et al. (1997) in a vigilance study, and Rainville et al. (1997) in a hypnosis study reported increases an activation in precuneus and cuneus area concurrent with a decrease in arousal and medial thalamic activity. In contrast, in the present study, thalamic deactivation is paralleled by medial occipital deactivation. We suggest that this is the reflection of a difference in the mechanism in play, namely the effect of naturally occurring changes in the level of arousal versus direct pharmacological effects of propofol.

$\mathrm{GABA}_{\mathrm{A}}$ receptors are distributed widely throughout the CNS, but Hendry et al. (1987) have reported that the primary visual cortex contains $50 \%$ more GABA-immunoreactive neurons than other cortical areas. This is a reflection of the overall higher density of neurons in the primary visual cortex and, therefore, a higher absolute number of GABA neurons compared with other cortical regions. It is possible that some cortical areas are more sensitive to the GABAergic inhibition caused by propofol on the basis of their network of corticocortical connections. Localized patterns of deactivation, like the one we report in the medial occipitotemporal area, might be enhanced on the basis of their connectivity network. Supportive evidence to this argument is given in a recent study by Chabli et al. (1998), who have shown that the inactivation of area 17 cells produces a decline of the evoked discharges in area 18 cells with the same orientation tuning.

We also report a significant decrease in $\mathrm{rCBF}$ in the orbitofrontal cortex bilaterally. This area of the frontal lobe is implicated in the modulation of emotional behavior and in the control of autonomic responses linked to generalized arousal reactions (Neafsey, 1990; Oppenheimer et al., 1992). It is part of a network that sends descending connections to the solitary nucleus of the brainstem (Neafsey et al., 1986). We speculate that the changes in $\mathrm{rCBF}$ in the orbitofrontal region during anesthesia might be related to a modification of autonomic outflow that contributes to a decrease in arterial blood pressure. However, further studies are required to provide evidence for that hypothesis.

Finally, we report an increase in $\mathrm{rCBF}$ in the cerebellum. This finding might be related to the initial increase in muscle tone and jerking movements frequently seen at early stages of propofolinduced general anesthesia.

Electroencephalographic activity recorded when consciousness 

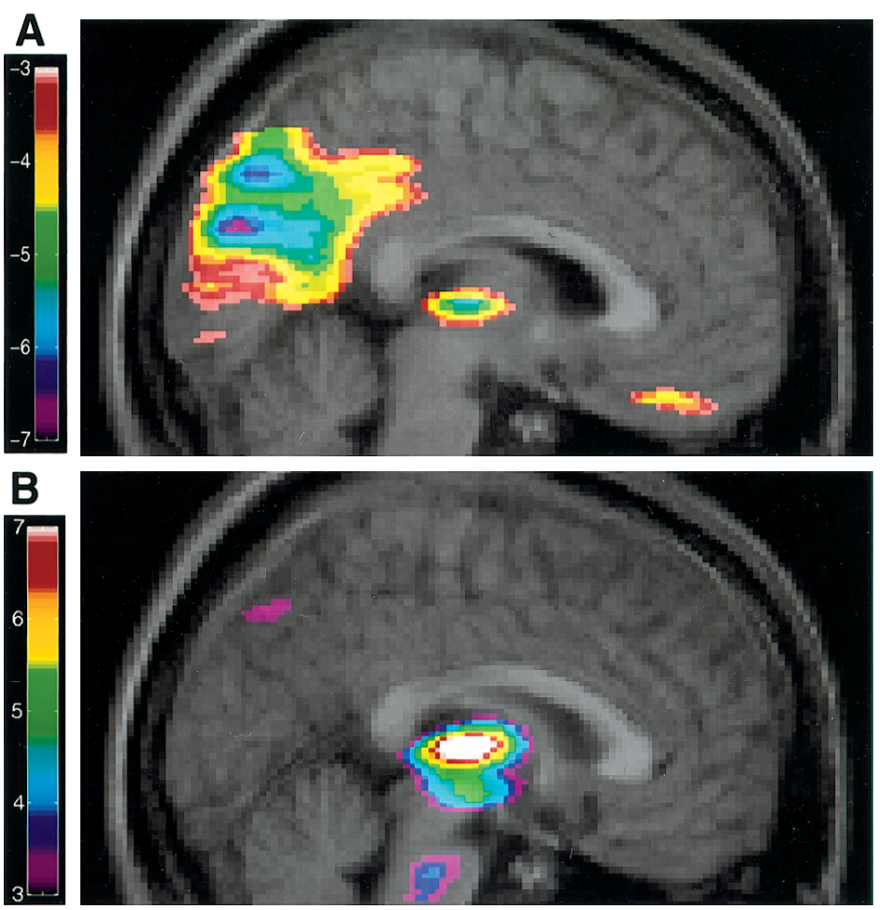

Figure 3. A, The merged $\mathrm{rCBF}-\mathrm{MRI}$ images indicate the location of the negative correlation of the regression between normalized rCBF and propofol concentration. The range of negative $t$ values for the PET data is coded by the color scale. $B$, Positive covariation between the thalamic $\mathrm{rCBF}$ and other brain structures. The range of positive values for the PET data is coded by the color scale.

was lost was characterized by high-amplitude, low-frequency $\delta$ waves and a decrease in $\gamma$ activity, an EEG pattern very similar to stage IV sleep. These findings are in accordance with the view that $\gamma$ activity is a property of the thalamocortical system associated with conscious processing.

\section{Conclusion}

The findings from the present study show that propofol induces concentration-dependent effects in the medial thalamus, cuneus, precuneus, and posterior cingulate and orbito-frontal cortices. This suggests that, at the concentrations attained (between 0.5 and $3.5 \mu \mathrm{g} / \mathrm{ml}$ plasma), propofol preferentially decreases $\mathrm{rCBF}$ in areas linked to the control of consciousness, associative functions (especially those related to visual inputs), and autonomic control. These changes have not been reported in previous studies concerned with the metabolic effects of propofol (Dam et al., 1990; Cavazzuti et al., 1991; Alkire et al., 1995).

The thalamic deactivation and its covariation with the midbrain reticular formation are consistent with the role of these structures in the control of consciousness. Moreover, they suggest that the $\mathrm{rCBF}$ changes reported in this study are linked to the specific effects of propofol on neuronal activity and are not the result of a nonspecific regional effect on CNS vasculature. In this context, the deactivation pattern in specific cortical regions suggests that some neuronal circuits are more sensitive to the effects of propofol and offers new avenues of investigation.

\section{REFERENCES}

Alkire MT, Haier RJ, Barker SJ, Shah NK, Wu JC, Kao J (1995) Cerebral metabolism during propofol anesthesia in humans studied with positron emission tomography. Anesthesiology 82:393-403.
Angel A (1993) Central neuronal pathways and the process of anaesthesia. Br J Anaesth 71:148-163.

Anis NA, Berry SC, Burton NR, Lodge D (1983) The dissociative anaesthetics, ketamine and phencyclidine, selectively reduce excitation of central mammalian neurons by N-methyl-aspartate. Br J Pharmacol 79:565-575.

Casati A, Fanelli G, Casaletti E, Colnaghi E, Cedrati V, Torri G (1999) Clinical assessment of target-controlled infusion of propofol during monitored anesthesia care. Can J Anaesth 46:235-239.

Cavazzuti M, Porro CA, Barbieri A, Galetti A (1991) Brain and spinal cord metabolic activity during propofol anaesthesia. Br J Anaesth 66:490-495.

Chabli A, Ruan DY, Molotchnikoff S (1998) Influences of area 17 on neuronal activity of simple and complex cells of area 18 in cats. Neuroscience 84:685-698.

Collins L, Neelin P, Peters T, Evans A (1994) Automatic 3D intersubject registration of MR volumetric data in standardized Talairach space. J Comput Assist Tomogr 18:192-205.

Concas A, Santoro G, Serra M, Sanna E, Biggio G (1991) Neurochemical action of the general anaesthetic propofol on the chloride ion channel coupled with $\mathrm{GABA}_{\mathrm{A}}$ receptors. Brain Res 542:225-232.

Dam M, Ori C, Pizzolato G, Ricchieri GL, Pellegrini A, Giron GP, Battistin L (1990) The effects of propofol anesthesia on local cerebral glucose utilization in the rat. Anesthesiology 73:499-505.

Destexhe A, Contreras D, Sejnowski TJ, Steriade M (1994) A model of spindle rhythmicity in the isolated thalamic reticular nucleus. J Neurophysiol 72:803-818.

Dunnet JM, Prys-Roberts C, Holland DE, Browne BL (1994) Propofol infusion and the suppression of consciousness: dose requirements to induce loss of consciousness and to suppress response to noxious and non-noxious stimuli. Br J Anaesth 72:29-34.

Electrode Nomenclature Committee (1994) Guideline thirteen: guidelines for standard electrode position nomenclature. J Clin Neurophysiol 11:111-113.

Eng C, Lam AM, Mayberg TS, Lee C, Mathisen T (1992) The influence of propofol with and without nitrous oxide on cerebral blood flow velocity and $\mathrm{CO}_{2}$ reactivity in humans. Anesthesiology 77:872-879.

Fiset P, Bonhomme V, Meuret P, Paus T, Plourde G, Backman S, Bushnell C, Evans AC (1997) Effects of propofol on regional cerebral blood flow during vibrotactile stumulation in man: a positron emission tomography (PET) study. Soc Neurosci Abstr 23:398.14.

Forrest FC, Tooley MA, Saunders PR, Prys-Roberts C (1994) Propofol infusion and the suppression of consciousness: the EEG and dose requirements. Br J Anaesth 72:35-41.

Frith C, Perry R, Lumer E (1999) The neural correlates of conscious experience: an experimental framework. Trends Cognit Sci 3:105-114.

Gjedde A (1997) The relation between brain function and cerebral flow and metabolism. In: Cerebrovascular disease (Hunt Bajter H, ed), pp 23-40. Philadelphia: Lippincott-Raven.

Hales TG, Lambert JJ (1991) The effects of propofol on inhibitory amino acid receptors of bovine adrenomedullary chromaffin cells and rodent central neurons. Br J Pharmacol 104:619-628.

Hendry SHC, Schwark HD, Jones EG, Yan J (1987) Numbers and proportions of GABA-immunoreactive neurons in different areas of monkey cerebral cortex. J Neurosci 7:1503-1519.

Hofle N, Paus T, Reutens D, Fiset P, Gotman J, Evans AC, Jones BE (1997) Covariation of regional cerebral blood flow with delta and spindle activity during slow wave sleep in humans. J Neurosci 17:4800-4808.

Jasper H (1949) Diffuse projection systems: the integrative action of the thalamic reticular system. Electroencephalogr Clin Neurophysiol 1:405-419.

Jones BE (1994) Basic mechanisms of sleep-wake states. In: Principles and practice of sleep medicine (Kryger MH, Roth T, Dement WC, eds), pp 145-162. Philadelphia: Saunders.

Keifer JC, Baghdoyan HA, Becker L, Lydic R (1994) Halothane decreases pontine acethylcholine release and increases EEG spindles. NeuroReport 5:577-580.

Kinney HC, Korein J, Panigrahy A, Dikkes P, Goode R (1994) Neuropathological findings in the brain of Karen Ann Quinlan. N Engl J Med 330:1469-1475.

Kinomura S, Larsson J, Gulyás B, Roland PE (1996) Activation by attention of the human reticular formation and thalamic intralaminar nuclei. Science 271:512-514. 
Kirk RE (1982) Experimental design: procedures for the behavioral sciences. Belmont, CA: Brooks/Cole.

Langerkranser M, Stange K, Sollevi A (1997) Effects of propofol on cerebral blood flow, metabolism, and cerebral autoregulation in the anesthetized pig. J Neurosurg Anesthesiol 9:188-193.

Llinás RR, Paré D (1991) Of dreaming and wakefulness. Neuroscience 44:521-535.

Lodge D, Anis NA, Burton NR (1982) Effects of optical isomers of ketamine on excitation of cat and rat spinal neurons by amino acids and acetylcholine. Neurosci Lett 29:281-286.

Lugaresi E, Medori R, Montagna P, Baruzzi A, Cortelli P, Lugaresi A, Tinuper P, Zucconi M, Gambetti P (1986) Fatal familial insomnia and dysautonomia with selective degeneration of thalamic nuclei. N Eng J Med 315:997-1003.

Lydic R, Keifer JC, Baghdoyan HA, Becker BS (1993) Microdialysis of the pontine reticular formation reveals inhibition of acetylcholine release by morphine. Anesthesiology 79:1003-1012.

Maquet P, Péters J-M, Aerts J, Delfiore G, Degueldre C, Luxen A, Franck G (1996) Functional neuroanatomy of human rapid-eye-movement sleep and dreaming. Nature 383:163-166.

Maquet P, Degueldre C, Delfiore G, Aerts J, Péters J-M, Luxen A, Franck G (1997) Functional neuroanatomy of human slow wave sleep. J Neurosci 17:2807-2812.

Moruzzi G, Magoun HW (1949) Brain stem reticular formation and activation of the EEG. Electroencephalogr Clin Neurophysiol $1: 455-473$.

Neafsey EJ (1990) Prefrontal cortical control of the autonomic nervous system: anatomical and physiological observations. Prog Brain Res 85:147-166.

Neafsey EJ, Hurley-Gius KM, Arvanitis D (1986) The topographical organization of neurons in the rat medial frontal, insular and olfactory cortex projecting to the solitary nucleus, olfactory bulb, periaqueductal gray and superior colliculus. Brain Res 377:261-270.

Newman MF, Murkin JM, Roach G, Croughwell ND, White WD, Clements FM, Reves JG (1995) Cerebral physiologic effects of burst suppression doses of propofol during nonpulsatile cardiopulmonary bypass. Anesth Analg 81:452-457.

Ohta S, Meyer E, Fujita H, Reutens DC, Evans A, Gjedde A (1996) Cerebral ${ }^{15} \mathrm{O}$ water clearance in humans determined by PET: I. Theory and normal values. J Cereb Blood Flow Metab 16:765-780.

Oppenheimer SM, Gelb A, Girvin JP, Hachinski VC (1992) Cardiovascular effects of human insular cortex stimulation. Neurology 42:1727-1732.

Orser B, Lu-Yang W, Pennefather PS, MacDonald JF (1994) Propofol modulates activation and desensitization of $\mathrm{GABA}_{\mathrm{A}}$ receptors in cultured murine hippocampal neurons. J Neurosci 14:7747-7760.

Paus T, Zatorre RJ, Hofle N, Caramanos Z, Gotman J, Petrides M, Evans AC (1997) Time-related changes in neural systems underlying attention and arousal during the performance of an auditory vigilance task. J Cognit Neurosci 9:392-408.

Pedutto VA, Concas A, Santoro G, Biggio G, Gessa GL (1991) Biochemical and electrophysiologic evidence that propofol enhances GABAergic transmission in the rat brain. Anesthesiology 75:1000-1009.

Pinaud M, Lelausque J-N, Chetanneau A, Fauchoux N, Ménégalli D, Souron R (1990) Effects of propofol on cerebral hemodynamics and metabolism in patients with brain trauma. Anesthesiology 73:404-409.

Plourde G, Boylan JF (1991) The auditory steady state response during sufentanil anaesthesia. Br J Anaesth 66:683-691.

Plourde G, Picton TW (1990) Human auditory steady-state response during general anesthesia. Anesth Analg 71:460-468.
Plourde G, Villemure C, Fiset P, Bonhomme V, Backman SB (1998) Effects of isoflurane on auditory steady state response and on unconsciousness in human volunteers. Anesthesiology 89:844-851.

Plummer GF (1987) Improved method for the determination of propofol in blood by high-performance liquid chromatography with fluorescence detection. J Chromatogr 421:171-176.

Raichle M, Martin W, Herscovitch P, Mintun M, Markham J (1983) Brain blood flow measured with intravenous $\mathrm{H}_{2} \mathrm{O}^{15}$ II. Implementation and validation. J Nucl Med 24:790-798.

Rainville P, Hofbauer RK, Paus T, Price DD, Bushnell MC, Duncan GH (1997) Cerebral correlates of hypnosis: comparison of delta EEG activity and regional cerebral blood flow (rCBF). Soc Neurosci Abstr 23:192.11.

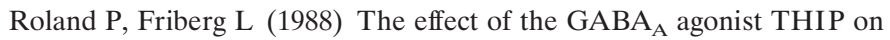
regional cortical blood flow in humans: a new test of hemispheric dominance. J Cereb Blood Flow Metab 8:314-323.

Salord F, Naous H, Rizk T, Guerin JM, Dailler F, Peillon D, Chacornac R (1995) Cerebrovascular reactivity to CO2 during general anesthesia maintained with either isoflurane-N2O or propofol-N2O. A comparative study by transcranial Doppler velocimetry. Ann Fr Anesth Reanim 14:166-171.

Sokal RR, Rohlf FJ (1981) Biometry. San Francisco: Freeman.

Steriade M, Deschenes M (1984) The thalamus as a neuronal oscillator. Brain Res 320:1-63.

Steriade M, Llinas RR (1988) The functional states of the thalamus and the associated neuronal interplay. Physiol Rev 68:649-742.

Steriade M, Jones EG, Llinás RR (1990) Brainstem control of the thalamus and states of vigilance. In: Thalamic oscillations and signaling (Steriade M, Jones EG, Llinás RR, eds), pp 313-364. New York: Wiley.

Steriade M, McCormick DA, Sejnowski TJ (1993) Thalamocortical oscillations in the sleeping and aroused brain. Science 262:679-685.

Tackley RM, Lewis GTR, Prys-Roberts C, Boaden RW, Dixon J, Harvey JT (1989) Computer controlled infusion of propofol. Br J Anaesth 62:46-53.

Talairach J, Tournoux P (1988) Co-planar stereotactic atlas of the human brain. New York: Thieme.

Tanelian DL, Kosek P, Mody I, MacIver B (1993) The role of the $\mathrm{GABA}_{\mathrm{A}}$ receptor/chloride channel complex in anesthesia. Anesthesiology 78:757-776.

Todd MM, Weeks J (1996) Comparative effects of propofol, pentobarbital, and isoflurane on cerebral blood flow and blood volume. J Neurosurg Anesthesiol 8:296-303.

Van Hemelrijck J, Fitch W, Mattheusen M, Van Aken H, Plets C, Lauwers T (1990) Effect of propofol on cerebral circulation and autoregulation in the baboon. Anesth Analg 71:49-54.

von Krosigk M, Bal T, McCormick DA (1993) Cellular mechanisms of a synchronized oscillation in the thalamus. Science 261:361-364.

Werner C, Hoffman WE, Kochs E, Schulte J, Albrecht RF (1993) The effects of propofol on cerebral and spinal cord blood flow in rats. Anesth Analg 76:971-975.

Woods R, Mazziotta J, Cherry S (1993) MRI-PET registration with automated algorithm. J Comput Assist Tomogr 17:536-546.

Worsley KJ, Evans AC, Marrett S, Neelin P (1992) Determining the number of statistically significant areas of activation in subtracted activation studies from PET. J Cereb Blood Flow Metab 12:900-918.

Yeh JZ, Quandt FN, Tanguy J, Nakahiro M, Narahashi T, Brunner EA (1991) General anesthetic action on gamma-aminobutyric acidactivated channels. Ann NY Acad Sci 625:155-173. 